\title{
Dantrolene in the Treatment of Refractory Hyperthermic Conditions in Critical Care: A Multicenter Retrospective Study
}

\author{
Shonali C. Pawar' ${ }^{1}$ Henry Rosenberg ${ }^{1,2 *}$, Robert Adamson ${ }^{3}$, Jennifer A. LaRosa ${ }^{4}$, \\ Ronald Chamberlain 1 \\ ${ }^{1}$ Department of Surgery, Saint Barnabas Medical Center, Livingston, USA \\ ${ }^{2}$ Department of Medical Education and Clinical Research, Saint Barnabas Medical Center, Livingston, USA \\ ${ }^{3}$ Corporate Pharmaceutical Sciences, Barnabas Health Care, Livingston, NJ, USA \\ ${ }^{4}$ Department of Pulmonary and Critical Care Medicine, Newark Beth Israel Medical Center, Newark, NJ, USA \\ Email: ${ }^{*}$ HRosenberg@barnabashealth.org
}

Received 24 March 2015; accepted 14 April 2015; published 15 April 2015

Copyright (C) 2015 by authors and Scientific Research Publishing Inc.

This work is licensed under the Creative Commons Attribution International License (CC BY).

http://creativecommons.org/licenses/by/4.0/

(c) (i) Open Access

\begin{abstract}
Purpose: To examine the use of intravenous dantrolene in hospitalized patients. Materials and Methods: Medical Records of patients treated with intravenous dantrolene between 2007 and 2012 at 6 teaching hospitals were reviewed. Temperature, muscle rigidity, creatine kinase levels, and mortality were assessed in association with dantrolene use. Results: Twenty-five patients received intravenous dantrolene, 9 patients with neuroleptic malignant syndrome (NMS), 8 with hyperthermia due to sepsis, 4 with NMS and sepsis, 2 for malignant hyperthermia (MH), and 2 with hypermetabolic syndrome associated with juvenile diabetic ketoacidosis. Dantrolene was administered as a bolus of $1-3 \mathrm{mg} / \mathrm{kg}$. Core temperature decreased after dantrolene administration in all groups but significant only for MH, NMS cases (Pre $102.3 \pm 0.9^{\circ} \mathrm{F}$ vs. Post $99.5 \pm 0.9^{\circ} \mathrm{F} ; p<0.001$ ), in Sepsis cases (Pre 104.3 $\pm 1.5^{\circ} \mathrm{F}$ vs. Post $100.6 \pm 1.0^{\circ} \mathrm{F} ; p<0.001$ ). Mean rigidity scores decreased in all groups but significant only for NMS cases, and mean CK did not change significantly in any group. Conclusion: Dantrolene was associated with reductions in temperature and rigidity in hyperthermia of diverse origins in patients admitted to Intensive care settings.
\end{abstract}

\section{Keywords}

Dantrolene, Malignant Hyperthermia, Neuroleptic Malignant Syndrome, Sepsis

\footnotetext{
${ }^{*}$ Corresponding author.
}

How to cite this paper: Pawar, S.C., et al. (2015) Dantrolene in the Treatment of Refractory Hyperthermic Conditions in Critical Care: A Multicenter Retrospective Study. Open Journal of Anesthesiology, 5, 63-71. 


\section{Introduction}

Hyperthermia with a core body temperature of $\geq 38.3^{\circ} \mathrm{C}\left(101^{\circ} \mathrm{F}\right)$ is frequently seen in the intensive care setting. Several syndromes including malignant hyperthermia (MH), neuroleptic malignant syndrome (NMS), serotonin syndrome, anticholinergic poisoning, heat stroke and sympathomimetic poisoning have been reported to be associated with hyperthermia [1]-[4]. Extreme hyperthermia with temperatures as high as $>41^{\circ} \mathrm{C}$ have been reported in some syndromes [5] [6]. Hyperthermia can be extremely harmful and potentially fatal because it may result in permanent neurologic sequelae like Cerebellar syndrome if not treated properly [7] [8]. The hyperthermia may eventually lead to life threatening complications, such as disseminated intravascular coagulation (DIC), renal failure, metabolic acidosis, cardiac dysfunction, and coma [7]-[9].

The mainstay of treatment in hyperthermic conditions includes withdrawal of triggers, supportive therapy with cooling techniques and pharmacotherapy aimed at reducing core body temperature [3]-[7]. Among the few pharmacological options available dantrolene a drug used in the treatment of MH may be beneficial in several hyperthermic conditions [10]-[13]. The common mechanism underlying rationale for use of dantrolene is the dysregulation of calcium as the major component of skeletal muscle generated heat in different hyperthermic conditions. It is known that dantrolene binds to ryanodine receptor (RYR-1) located in the skeletal muscle, reducing the release of calcium from the sarcoplasmic reticulum and thereby inhibiting skeletal muscle contraction [14] [15]. Dantrolene is specifically indicated for the treatment of MH and lowers mortality from the syndrome [15] [16]. In addition to MH, dantrolene has been recommended for the treatment of NMS [17] [18]. However, the role of dantrolene is not well defined in the treatment of NMS as it is in the treatment of MH. Studies have documented a steady decrease in mortality since 1984 from $26 \%$ to $11 \%$, independent of the treatment used: dopamine agonist or dantrolene [19]. There are also reports that do not support the efficacy of dantrolene in NMS [20] [21]. Recently a report documented that dantrolene along with antibiotics was efficacious in the treatment of toxic shock syndrome from staphylococcal enterotoxins [22]. Brian et al. conducted a systematic review on the use of dantrolene for MDMA (3, 4 methylene dioxy methamphetamine)—related hyperthermia in 71 patients, and concluded that dantrolene is not only safe but also conferred survival benefit, reduced complications, especially in patients with extreme $\geq 42^{\circ} \mathrm{C}$ hyperthermia [13].

This multicenter retrospective case series reviewed the indications and outcomes of intravenous dantrolene treatment in clinical practice. The purpose of this study was to determine if dantrolene use was associated with changes in core body temperatures, degree of muscle rigidity, creatine kinase levels, and mortality in different hyperthermic conditions.

\section{Materials and Methods}

\subsection{Study Setting}

The retrospective analysis was approved by the Institutional Review Boards at 6 different tertiary care centers within the Barnabas Health Care System (registration no's: 12 - 75; 13 - 67; 13 - 69; 2013.02; 13-001; 13-002). University-affiliated teaching hospitals [Saint Barnabas Medical Center, Newark Beth Israel Medical Center, Community Medical Center, Clara Maass Medical Center, Kimball Medical Center, and Monmouth Medical Center] with approximately 20,000 - 32,000 admissions annually, participated in the study. Pharmacy database records were systematically reviewed, identifying all adult and pediatric patients who received dantrolene from January 2007 through December 2012.

\subsection{Study Population}

Patients were included in this series if they were administered dantrolene intravenously. Patients were excluded if they were prescribed oral dantrolene only. In general, dantrolene was given to patients with hyperthermias of different etiology in an ICU setting (Figure 1). The principal diagnosis was made by the treating physicians (critical care consultant) and confirmed upon review of the medical records by two investigators [S.P, H.R] in this series. NMS was determined by clinical diagnosis and was confirmed in each case using the Levenson criteria for NMS [23]. Sepsis was determined by presence of two out of four criteria for systemic inflammatory response syndrome with a documented source of infection for sepsis [24]. The decision to administer dantrolene was made by the anesthesiologist for cases with $\mathrm{MH}$, and by treating critical care consultant for other cases. 


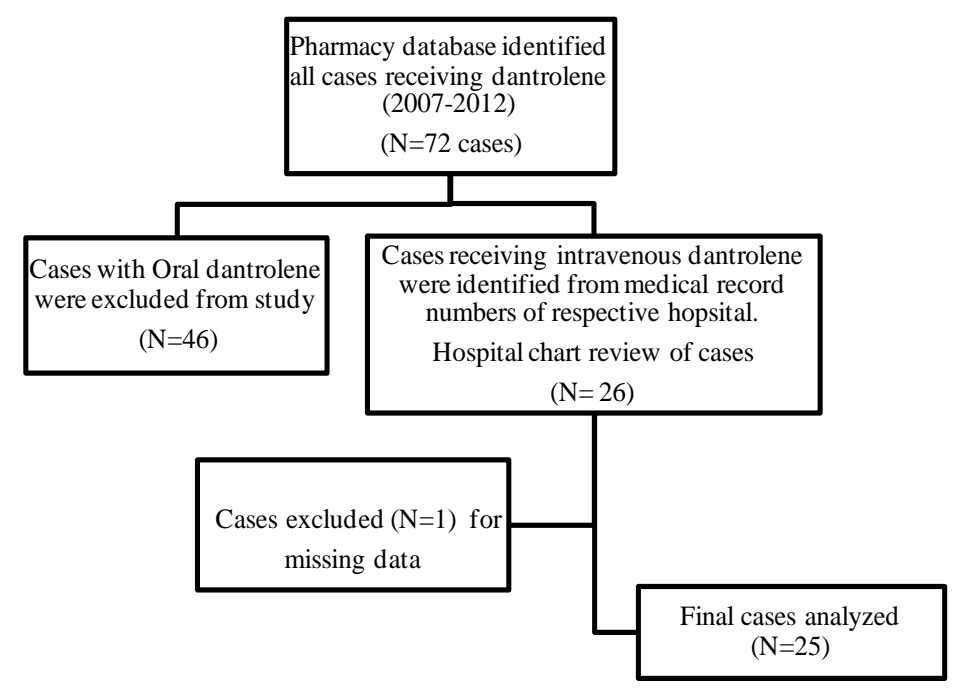

Figure 1. Flow diagram showing the records selection process.

\subsection{Data Collection and Analysis}

A standard data collection form was used. The form was designed by two investigators and approved by ethics committee. Baseline demographic and clinical information collected included age, gender, Acute Physiology and Chronic Health Evaluation score II (APACHE II) score at baseline, clinical presentation (chief complaint at the time of admission to the hospital), principal diagnosis, all medications taken prior to the onset of fever. Pertinent clinical information included temperature in Fahrenheit, creatine kinase levels, degree of muscle rigidity determined by the Critical Care Consultant, the time to resolution of symptoms, the total dose of dantrolene, and bolus dose in $\mathrm{mg} / \mathrm{kg}$, and in hospital mortality. Data outliers were screened and detected sing scatter plots. After careful review, missing, miscoded data and outliers were deleted from final analysis.

\subsection{Outcomes}

Outcomes evaluated in this study included the impact of dantrolene on clinical parameters of hypermetabolic state, and mortality. Specific outcomes measured in terms of clinical response to administration of dantrolene were reduction in temperature, reduction in creatine kinase levels, and reduction in rigidity. Rigidity was graded using the four point rating scale (Sachdev scale): 0, nil (no rigidity); 1 mild (+), slight rigidity present, particularly obvious on recruitment of muscles with jaw clenching, 2 moderate (++), definitely present to a significant degree but produces no limitation of passive movement; 3 severe $(+++)$, rigidity that produces some limitation of passive movement [25]. The frequency of measurements varied depending on the principal diagnosis. The clinical parameters (core body temperature, degree of rigidity, and creatine kinase levels) within 24 hours interval prior to first (loading dose) of dantrolene, a reading within 24 hours following the administration, and within 48 hours following the administration were used for analysis.

We classified patients into three categories depending on their response to intravenous dantrolene (Figure 2). Group 1 (Effective response group) included patients where dantrolene use was associated with reduction in all three clinical parameters temperature, creatine kinase levels and degree of rigidity. Group 2 (Partially effective) included patients where one or two of the 3 clinical parameters responded: temperature or creatine kinase levels or reduced rigidity. Group 3 included patients where there was no clinical effect despite the use of dantrolene.

\subsection{Statistical Analysis}

Data were analyzed using Post Hoc paired sampled "T" test. Pre and post dantrolene core temperatures, creatine kinase levels, and degree of muscle rigidity are displayed as mean and standard deviations in patients with various hyperthermias. P value less than 0.05 was considered statistically significant. SAS statistical software version 9.3 (SAS Institute NC) was used for analyses. 


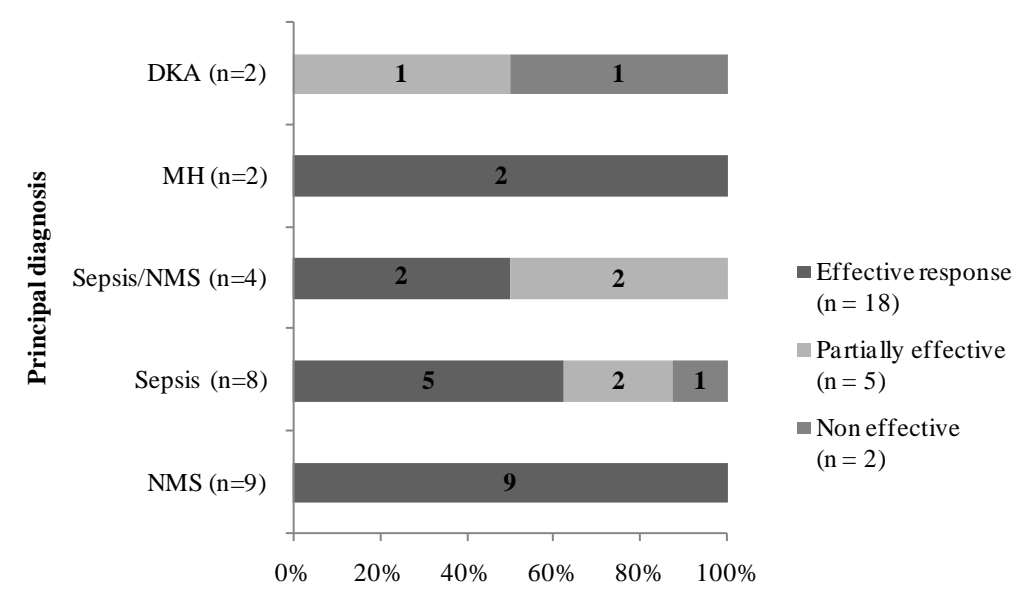

Figure 2. Overall response to dantrolene administration in 25 patients. Abbreviations: Data is presented as number of patients (n); NMS, neuroleptic malignant syndrome; DKA, diabetic ketoacidosis; $\mathrm{MH}$, malignant hyperthermia; Effective response, dantrolene use was associated with a lowered temperature, lowered creatine kinase levels and lowered degree of rigidity; Partially effective, lowered either 1 or 2 of the 3 clinical parameters; Non effective, no effect.

\section{Results}

\subsection{Demographics and Clinical Characteristics}

The health care system pharmacy database identified 72 patients who received dantrolene during the period from January 2007 to December 2012. We excluded patients $(n=46)$ who received oral dantrolene. Twenty-six patients received intravenous dantrolene. We excluded 1 patient receiving intravenous dantrolene with the diagnosis of cocaine toxicity because of an incomplete medical record. The principal diagnosis of patients receiving intravenous dantrolene sodium included neuroleptic malignant syndrome $(n=9)$, sepsis $(n=8)$ sepsis and NMS $(n=4)$, malignant hyperthermia $(n=2)$, and juvenile diabetic ketoacidosis $(n=2)$. The demographic and clinical characteristics of the patients included are shown in Table 1. Sixty percent of those receiving dantrolene were male. Their age ranged 10 - 82 year. Patients receiving dantrolene were critically ill; as their APACHE II score was very high with a mean of $30 \pm 5$ and $80 \%$ of them had multiple underlying comorbidities. The overall mortality in the series was $32 \%$. Six died from sepsis and two from diabetic ketoacidosis. 4 out of 8 Patients who died also had an initial presentation of multi organ failure. Overall the mean and maximum core body temperature recorded was $102.3^{\circ} \mathrm{F}$ and $106^{\circ} \mathrm{F}$ respectively. Creatine kinase levels between 234 and 256,389 IU/L. The medications used prior to onset of fever in patients with NMS and, anesthetic agents triggering $\mathrm{MH}$, and microorganisms identified in patients with sepsis are listed in Table 1 . The time to resolution of symptoms ranged between $5-17$ days in patients with NMS, 5 - 58 days in sepsis, 2 - 3 days in MH. Among 8 cases of sepsis 3 were documented to have staphylococcal toxic shock syndrome. Four patients with NMS also had sepsis with positive blood cultures, hence were grouped under the separate category of sepsis and NMS. Four of the 8 cases of sepsis had multi organ failure before their first dose of dantrolene was administered.

\subsection{Dantrolene Administration}

Dantrolene was administered as a bolus dose ranging $2.5-3.0 \mathrm{mg} \cdot \mathrm{kg}^{-1}$ and was repeated at 5 min intervals until normalization of hypermetabolic state for $\mathrm{MH}$ cases. Dantrolene was administered as bolus ranging 1 - 2.5 $\mathrm{mg} \cdot \mathrm{kg}^{-1}$ and was repeated every 6 hours until resolution of hyperthermia in patients with NMS, sepsis and diabetic ketoacidosis. Dantrolene was administered immediately in patients with MH. For patients with NMS, dantrolene was administered later in the course of treatment only after introduction of bromocriptine, supportive care.

\subsection{Outcomes}

The overall response to dantrolene administration in 25 patients with hyperthermia of different etiology is shown in Figure 2. Clinical outcomes related to intravenous dantrolene treatment are described in Figure 3. There was a 
Table 1. Clinical, pharmacologic, and laboratory data on 25 patients with hyperthermias of different etiology treated with dantrolene (2007-2012).

\begin{tabular}{|c|c|c|c|c|c|c|c|c|c|c|}
\hline ? & 串点 & 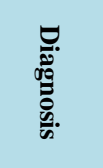 & 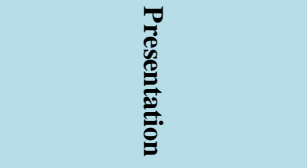 & 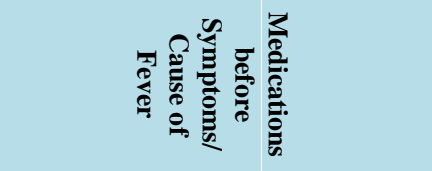 & 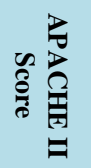 & 氞总 & 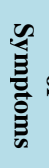 & 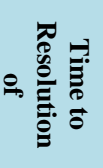 & 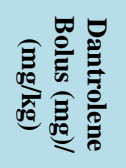 & 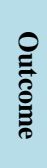 \\
\hline 1 & $\mathrm{M} / 44$ & NMS & Altered Consciousness & Haloperidol, Metoclopramide & 16 & 102.5 & & 5 & $250 /(2.5)$ & $\mathrm{R}$ \\
\hline 2 & $\mathrm{M} / 41$ & NMS & Altered Consciousness & Haloperidol, Ziprasidone & 12 & 101.4 & & 11 & $235 /(1.5)$ & $\mathrm{R}$ \\
\hline 3 & $\mathrm{M} / 39$ & NMS & Involuntary Movements & Quetiapine & 10 & 102 & & 9 & 100/(2) & $\mathrm{R}$ \\
\hline 4 & $\mathrm{M} / 56$ & NMS & Altered Consciousness & $\begin{array}{l}\text { Escitalopram, Topiramate, } \\
\text { Biperiden, Clozapine }\end{array}$ & 22 & 101.1 & & 14 & $58 /(1)$ & $\mathrm{R}$ \\
\hline 5 & $\mathrm{~F} / 63$ & NMS & Altered Consciousness & Quetiapine & 13 & 101.3 & & 17 & $75 /(1)$ & $\mathrm{R}$ \\
\hline 6 & $\mathrm{M} / 56$ & NMS & Altered Consciousness & Risperidone, & 19 & 103 & & 9 & $100 /(1.5)$ & $\mathrm{R}$ \\
\hline 7 & $\mathrm{M} / 67$ & NMS & Altered Consciousness & Levetiracetam, Clonazepam & 21 & 102 & & 10 & $250 /(2)$ & $\mathrm{R}$ \\
\hline 8 & $\mathrm{M} / 39$ & NMS & Altered Consciousness & Ziprasidone, Haloperidol & 13 & 100.3 & & 8 & $375 /(2.5)$ & $\mathrm{R}$ \\
\hline 9 & $\mathrm{M} / 65$ & NMS & Hyperthermia, Agitation & Citalopram, Quetiapine, Haloperidol & 20 & 102 & & 11 & $375 /(2.5)$ & $\mathrm{R}$ \\
\hline 10 & $\mathrm{M} / 32$ & MH & Hyperthermia/Acidosis & Desflurane & 15 & 101.1 & & 2 & 345/(3) & $\mathrm{R}$ \\
\hline 11 & $\mathrm{~F} / 55$ & MH & Hyperthermia/Acidosis & Sevoflurane & 17 & 102.4 & & 3 & $355 /(2.5)$ & $\mathrm{R}$ \\
\hline 12 & M/39 & Sepsis & Abdominal Pain & Klebsiella puemoniae & 26 & 104 & & 12 & $480 /(2)$ & $\mathrm{D}$ \\
\hline 13 & $\mathrm{~F} / 61$ & sepsis & Fever/Perforated Bowel & Escherichia coli & 34 & 104 & & 58 & $400 /(2.5)$ & $\mathrm{R}$ \\
\hline 14 & $\mathrm{~F} / 51$ & Sepsis & Intracranial Hemorrhage & Staphylococcus aureus & 31 & 104.3 & & 21 & 225/(3) & $\mathrm{R}$ \\
\hline 15 & $\mathrm{M} / 52$ & Sepsis & Pneumonia & Streptococcus puemoniae & 30 & 101.6 & & 17 & $235 /(2.5)$ & $\mathrm{R}$ \\
\hline 16 & $\mathrm{~F} / 82$ & Sepsis & Staphylococcal Infection & Staphylococcus aureus & 36 & 102 & & 9 & $100 /(2.0)$ & $\mathrm{D}$ \\
\hline 17 & $\mathrm{M} / 19$ & Sepsis & Convulsions/Pneumonia & Streptococcus pyogenes & 35 & 101.6 & & 29 & $160 /(1.8)$ & $\mathrm{R}$ \\
\hline 18 & M/39 & Sepsis & Aortic Dissection & Staphylococcus aureus & 46 & 104 & & 5 & $200 /(2.5)$ & $\mathrm{D}$ \\
\hline 19 & $\mathrm{~F} / 11$ & Sepsis & Septic Shock & Escherichia coli & 49 & 102 & & 11 & $85 /(1.0)$ & $\mathrm{D}$ \\
\hline 20 & $\mathrm{M} / 67$ & NMS/S & Altered Mental Status & Staphylococcus aureus/Ziprasidone & 55 & 102.4 & & 5 & 250/(3) & $\mathrm{D}$ \\
\hline 21 & $\mathrm{~F} / 67$ & NMS/S & Autonomic Disturbances & $\begin{array}{c}\text { Staphylococcus aureus/quetiapine, } \\
\text { Thioridazine }\end{array}$ & 35 & 102.0 & & 13 & $75 /(1)$ & $\mathrm{R}$ \\
\hline 22 & $\mathrm{~F} / 10$ & NMS/S & Seizures & Staphylococcus aureus/Ziprasidone & 44 & 102.4 & & 15 & $160 /(2)$ & $\mathrm{R}$ \\
\hline 23 & $\mathrm{~F} / 71$ & NMS/S & Altered Mental Status & $\begin{array}{c}\text { Streptococcus } \\
\text { viridans/Escitalopram, Clonazepam, } \\
\text { Amantadine }\end{array}$ & 49 & 104 & & 5 & $125 /(2.5)$ & $\mathrm{D}$ \\
\hline 24 & $\mathrm{~F} / 15$ & DKA & Fever/Polyuria/Polydipsia & Unclear & 41 & 106 & & 4 & $150 /(2.5)$ & $\mathrm{D}$ \\
\hline 25 & $\mathrm{M} / 19$ & DKA & Seizures/Hyperthermia & Unclear & 45 & 103 & & 3 & $100 /(2.5)$ & $\mathrm{D}$ \\
\hline
\end{tabular}

Abbreviations: NMS, Neuroleptic Malignant Syndrome; DKA, Diabetic Ketoacidosis; MH, Malignant Hyperthermia; S, Sepsis; CK, Creatine Kinase; F, Fahrenheit; R, Recovered; D, Died. Case 23 had an abrupt withdrawal of amantadine. 

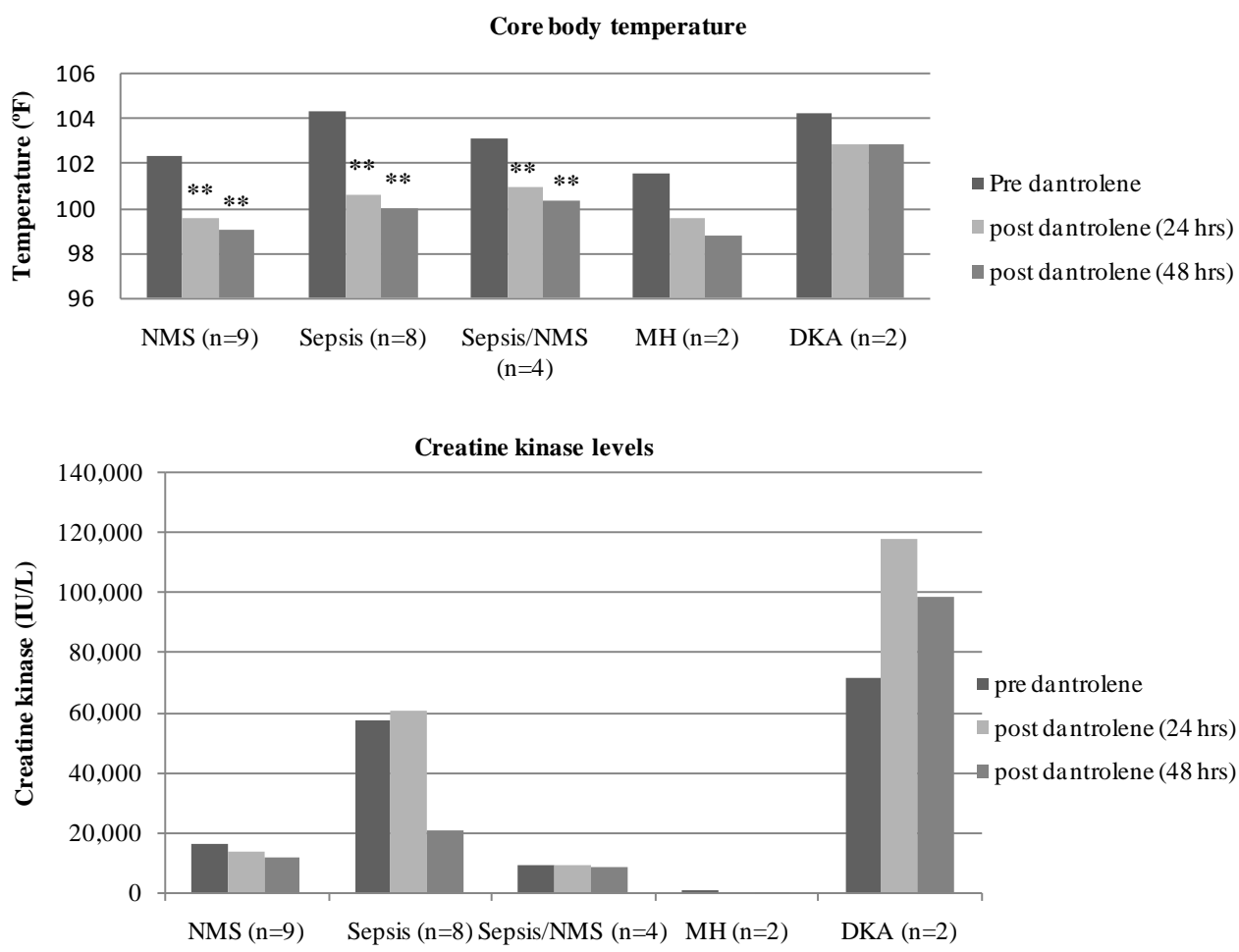

Degree of muscle rigidity

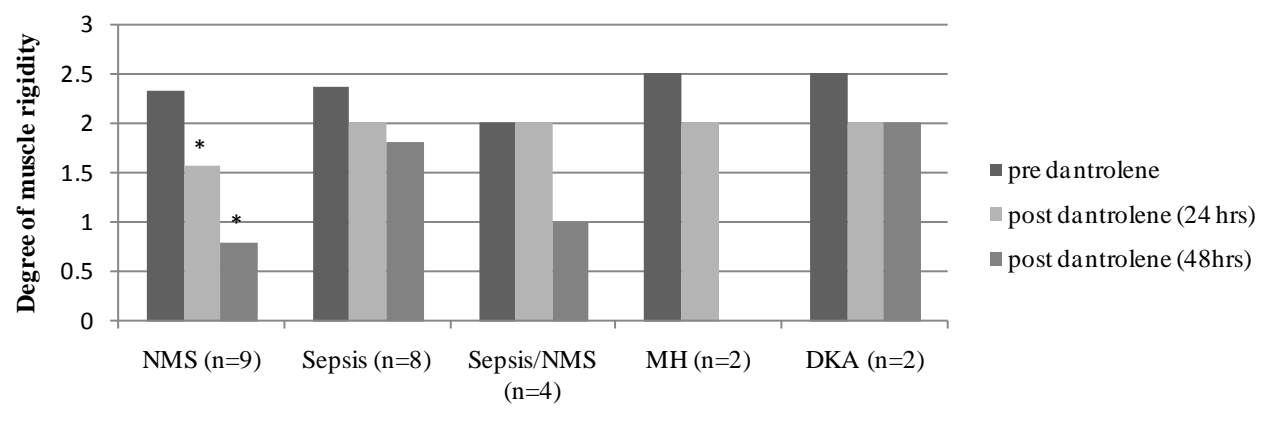

Figure 3. Changes in core body temperature, creatine kinase levels, and degree of muscle rigidity in response to dantrolene in 25 patients with hyperthermia of different etiology. Muscle rigidity post $48 \mathrm{hr}$ in patients with $\mathrm{MH}$ was absent, was scored 0 . (Numbers presented are Mean \pm Standard deviation. $p$ value is calculated using paired sampled "T" test, $p<0.05$ as statistically significant value. ${ }^{*} p<0.05,{ }^{* *} p$ $<0.001, \stackrel{* * *}{p}<<0.0001)$.

statistically significant reduction in mean core temperature after administration of dantrolene bolus in NMS, and Sepsis cases within first 24 hours. Although there was a decrease in core temperature seen in other conditions, analysis could not be performed due to the small number of patients in each category. Overall there was a steady decrease in serum CK levels in the first 24 hours and continued to decline in the following 48 hours in 23/25 cases, however the result did not reach statistical significance. CK levels among the 25 patients showed a huge variance and standard deviation (give the data here). Overall there was a decrease in degree of skeletal muscle rigidity in 23/25 cases, and was statistically significant in NMS patients both at 24 hours and $48 \mathrm{hr}$ post dantrolene administration. The details are demonstrated in Figure 3 outcomes.

\section{Discussion}

This clinical report is unique as it provides evidence that dantrolene is associated with favorable outcome in some patients with extreme hyperthermia related to drugs or sepsis. The study demonstrates that use of dantrolene is not 
limited to treating malignant hyperthermia of anesthesia; but the drug is being used in the treatment of extreme hyperthermia from a number of different causes. Between 2007 and 2012 dantrolene was given to patients with NMS, sepsis, MH, and Juvenile DKA to combat severe hyperthermic and metabolic illness, when the patient had not responded to supportive care and standard medical treatment. With the exception of patients with $\mathrm{MH}$, the drug was primarily administered as a last resort therapy to manage extreme hyperthermia. Dantrolene administration was associated with statistically significant reduction in core body temperatures within 24 hours in 24 out of 25 patients regardless of the cause and severity of fever. Another important finding was the associated progressive and sustained reduction in creatine kinase levels and a statistically significant reduction in the degree of muscle rigidity within 24 hours of its administration in NMS. The study group comprised of severely sick (high APACHE score) patients with multiple comorbidities, which might explain the high mortality in this series compared to patients in other reports [12] [20] [21] [26].

In NMS, the use of any of the medications bromocriptine, dantrolene, or amantadine is controversial and largely unsupported mainly because of lack of any randomized trials given the rarity of NMS. A review of the literature shows that dantrolene sometimes is associated with a good outcome but sometimes is not [18] [20] [21] [27] [28]. A review of 64 cases concluded that the addition of dantrolene and or bromocriptine to conservative measures decreased the time to clinical response [27]. Another retrospective analysis by Sakkas et al. found lower mortality (NMS related death rate) in patients treated with dantrolene alone 8.6\%, 7.8\% with bromocriptine alone, 5.9\% with amantadine alone, 21\% with supportive treatment alone [28]. In contrast to these 2 review studies, a nonrandomized prospective study in 20 patients showed dantrolene and or bromocriptine was associated with a more prolonged course and higher incidence of sequelae compared with supportive care alone [21]. Most of these studies measure in hospital mortality and time to remission, with less attention paid to effectiveness in terms of actual decrease in core temperature, metabolism and rigidity. Our report demonstrates the changes in temperature, rigidity and CK levels during and after the 24 hour control window of dantrolene administration. We conclude that dantrolene in combination with other agents is of benefit in resolving symptoms in severe NMS.

The role of dantrolene in sepsis, and DKA is less clear. A malignant hyperthermia like syndrome (MHLS) of unclear cause has been reported in children with hyperglycemic crisis without known exposure to anesthetic triggers [29]-[32]. The term was first coined by Hollander to describe patients in hyperglycemic crisis presenting with rhabdomyolysis and high grade fever. Dantrolene has been used with some success in resolving hyperpyrexia in MHLS [32]. Similarly the use of dantrolene in sepsis is rarely cited in literature [33]. Ginz and colleagues report the use of dantrolene to reduce skeletal muscle hypermetabolism in a patient with staphylococcal toxic shock syndrome leading to a favorable patient outcome [22]. Of particular interest in our series is the decrease in body temperatures associated with the use of dantrolene, irrespective of the severity of sepsis. However, these results should be interpreted with caution since in addition to dantrolene these patients also received other medical treatments (antibiotics).

There are certain limitations to this study. This was a retrospective case series of very ill patients who received dantrolene based on the decision of the treating physician. Also, the assessment of rigidity was subject to observer bias, as there was no uniformity maintained in regards to the observer. The lack of control group limits the possibility of exploring the efficacy of dantrolene in contrast to others. None of these patients were treated with dantrolene alone, hence could be confounded by various other medical. The severity and rarity of these cases makes them unique, but limits the ability to extrapolate these results to patients of lower acuity level.

\section{Conclusions}

Despite its many limitations, our study supports, the use of dantrolene in extreme hyperthermia accompanied by skeletal muscle rigidity, and elevated creatine kinase levels. The study however does not prove the efficacy or safety of dantrolene in various hyperthermic syndromes not related to the malignant hyperthermia syndrome of anesthesia. The results justify a larger prospective study comparing dantrolene to more standard treatment of hyperthermia. Additionally, further investigations are needed to clarify the mode of action of the dantrolene in such conditions.

Conflicts of interest on behalf of all authors, the corresponding author states that there is no conflict of interest.

\section{Acknowledgements}

The authors acknowledge the significant efforts of Tanya Vialet, Research Manager, Saint Barnabas Medical 
Center, for her vital assistance in the Institutional Review Boards' application and submission processes, in order to attain approval for access to the hospital charts.

\section{References}

[1] Gillman, P.K. (2010) Neuroleptic Malignant Syndrome: Mechanisms, Interactions, and Causality. Movement Disorders, 25, 1780-1790. http://dx.doi.org/10.1002/mds.23220

[2] Wappler, F. (2001) Malignant Hyperthermia. European Journal of Anaesthesiology, 18, 632-652. http://dx.doi.org/10.1046/j.1365-2346.2001.00888.x

[3] Musselman, M.E. and Saely, S. (2013) Diagnosis and Treatment of Drug-Induced Hyperthermia. American Journal of Health-System Pharmacy, 70, 34-42. http://dx.doi.org/10.2146/ajhp110543

[4] Eyer, F. and Zilker, T. (2007) Bench to Bedside Review: Mechanisms and Management of Hyperthermia Due to Toxicity. Critical Care, 11, 236. http://dx.doi.org/10.1186/cc6177

[5] McAllen, K.J. and Schwartz, D.R. (2010) Adverse Drug Reactions Resulting in Hyperthermia in the Intensive Care Unit. Critical Care Medicine, 38, 244-252. http://dx.doi.org/10.1097/CCM.0b013e3181dda0d4

[6] Boyer, E.W. and Shannon, M. (2005) The Serotonin Syndrome. The New England Journal of Medicine, 352, 11121120. http://dx.doi.org/10.1056/NEJMra041867

[7] Lefkowitz, D., Ford, C.S., Rich, C., Biller, J. and McHenry Jr., L.C. (1938) Cerebellar Syndrome Following Neuroleptic Induced Heat Stroke. Journal of Neurology Neurosurgery and Psychiatry, 46, 183-185. http://dx.doi.org/10.1136/jnnp.46.2.183

[8] Hadad, E., Weinbroum, A.A. and Ben-Abraham, R. (2003) Drug Induced Hyperthermia and Muscle Rigidity: A Practical Approach. European Journal of Emergency Medicine, 10, 149-154. http://dx.doi.org/10.1097/00063110-200306000-00018

[9] Adnet, P., Levstavel, P. and Krivosic-Horber, R. (2000) Neuroleptic Malignant Syndrome. British Journal of Anaesthesia, 85, 129-135. http://dx.doi.org/10.1093/bja/85.1.129

[10] Denborough, M.A. (1982) Heat Stroke and Malignant Hyperpyrexia. The Medical Journal of Australia, 1, $204-205$.

[11] Meyers, E.F. and Meyers, R.W. (1982) Thermic Stress Syndrome. JAMA, 247, 2098-2099. http://dx.doi.org/10.1001/jama.1982.03320400018018

[12] Strawn, J.R., Keck, P.E. and Caroff, S.N. (2007) Neuroleptic Malignant Syndrome. American Journal of Psychiatry, 164, 870-876. http://dx.doi.org/10.1176/ajp.2007.164.6.870

[13] Grunau, B.E., Wiens, M.O. and Brubacher, J.R. (2010) Dantrolene in the Treatment of MDMA-Related Hyperpyrexia: A Systematic Review. Canadian Journal of Emergency Medicine, 12, 435-442.

[14] Kurz, A. (2008) Physiology of Thermoregulation. Best Practice \& Research Clinical Anaesthesiology, 22, 627-644. http://dx.doi.org/10.1016/j.bpa.2008.06.004

[15] Krause, T., Gerbershagen, M.U., Fiege, M., Weibhorn, R. and Wappler, F. (2004) Dantrolene-A Review of Its Pharmacology, Therapeutic Use and New Developments. Anaesthesia, 59, 364-373.

[16] Rosenberg, H., Davis, M., James, D., Pollock, N. and Stowell, K. (2007) Malignant Hyperthermia. Orphanet Journal of Rare Diseases, 2, 21. http://dx.doi.org/10.1186/1750-1172-2-21

[17] Davis, J.M., Caroff, S.N. and Mann, S.C. (2000) Treatment of Neuroleptic Malignant Syndrome. Psychiatric Annals, 30, 325-331. http://dx.doi.org/10.3928/0048-5713-20000501-10

[18] Caroff, S.N. (2003) Neuroleptic Malignant Syndrome. In: Man, S.C., Caroff, S.N., Keck Jr., P.E. and Lazarus, A., Eds., Neuroleptic Malignant Syndrome and Related Conditions, 2nd Edition, American Psychiatric Publishing, Washington, DC, 1-44.

[19] Shalev, A., Hermesh, H. and Munitz, H. (1989) Mortality from Neuroleptic Malignant Syndrome. Journal of Clinical Psychiatry, 50, 18-25.

[20] Reulbach, U., Dutsch, C., Biermann, T., Sperling, W., Thuerauf, N., Kornhuber, J. and Bleich, S. (2007) Managing an Effective Treatment for Neuroleptic Malignant Syndrome. Critical Care, 11, R4.

[21] Rosebush, R.L., Stewart, T. and Mazurek, M.F. (1991) The Treatment of Neuroleptic Malignant Syndrome. Are Dantrolene and Bromocriptine Useful Adjuncts to Supportive Care? British Journal of Psychiatry, 159, 709-712. http://dx.doi.org/10.1192/bjp.159.5.709

[22] Ginz, H.F., Levano, S., Girard, T., Urwyler, A. and Hamel, C. (2012) Dantrolene for Severe Rhabdomyolysis in Staphylococcus aureus Toxic Shock Syndrome. European Journal of Anaesthesiology, 29, 161-162. http://dx.doi.org/10.1097/EJA.0b013e32834c7c9d

[23] Levenson, J.L. (1985) Neuroleptic Malignant Syndrome. American Journal of Psychiatry, 142, 1137-1145. 
http://dx.doi.org/10.1176/ajp.142.10.1137

[24] ACCP/SCCM (1992) American College of Chest Physicians/Society of Critical Care Medicine Consensus Conference: Definitions of Sepsis and Organ Failure and Guidelines for the Use on Innovative Therapies in Sepsis. Critical Care Medicine, 20, 864-874. http://dx.doi.org/10.1097/00003246-199206000-00025

[25] Sachdev, P.S. (2005) A Rating Scale for Neuroleptic Malignant Syndrome. Psychiatry Research, 135, $249-256$. http://dx.doi.org/10.1016/j.psychres.2005.05.003

[26] Nisijima, K. and Shioda, K. (2013) Temporal Changes in Serum Creatine Kinase Concentration and Degree of Muscle Rigidity in 24 Patients with Neuroleptic Malignant Syndrome. Neuropsychiatric Disease and Treatment, 9, 853-859. http://dx.doi.org/10.2147/NDT.S45084

[27] Rosenberg, M.R. and Green, M. (1989) Neuroleptic Malignant Syndrome. Review of Response to Therapy. JAMA Internal Medicine, 149, 1927-1931. http://dx.doi.org/10.1001/archinte.1989.00390090009002

[28] Sakkas, P., Davis, J.M., Janicak, P.G. and Wang, Z.Y. (1991) Drug Treatment of the Neuroleptic Malignant Syndrome. Psychopharmacology Bulletin, 27, 381-384.

[29] Hollander, A.S., Olney, R.C., Blackett, P.R. and Marshall, B.A. (2003) Fatal Malignant Hyperthermia Like Syndrome with Rhabdomyolysis Complicating the Presentation of Diabetes Mellitus in Adolescent Males. Pediatrics, 111, 14471452. http://dx.doi.org/10.1542/peds.111.6.1447

[30] Morales, A.E. and Rosenbloom, A.L. (2004) Death Caused by Hyperglycemic Hyperosmolar State at the Onset of Type 2 Diabetes. Journal of Pediatrics, 144, 270-273. http://dx.doi.org/10.1016/j.jpeds.2003.10.061

[31] Carchman, R.M., Dechert-Zeger, M., Calikoglu, A.S. and Harris, B.D. (2005) A New Challenge in Pediatric Obesity: Pediatric Hyperglycemic Hyperosmolar Syndrome. Pediatric Critical Care Medicine, 6, 20-24. http://dx.doi.org/10.1097/01.PCC.0000149134.61673.77

[32] Kilbane, B.J., Mehta, S., Backeljauw, P.F., Shanley, T.P. and Crimmins, N.A. (2006) Approach to Management of Malignant Hyperthermia-Like Syndrome in Pediatric Diabetes Mellitus. Pediatric Critical Care Medicine, 7, 169-173. http://dx.doi.org/10.1097/01.PCC.0000192340.09136.82

[33] Hotchkiss, R.S. and Karl, I.E. (1994) Dantrolene Ameliorates the Metabolic Hallmarks of Sepsis in Rats and Improves Survival in a Mouse Model of Endotoxemia. Proceedings of the National Academy of Sciences of the United States of America, 91, 3039-3043. http://dx.doi.org/10.1073/pnas.91.8.3039 